\title{
FISH SCALE IDENTIFICATION: FROM INDIVIDUAL TO SPECIES-SPECIFIC SHAPE VARIABILITY
}

\author{
Zsuzsanna Bräger ${ }^{1,2 *}$, Ádám Staszny ${ }^{3}$, Matthias Mertzen ${ }^{1,4}$, Timo Moritz ${ }^{1,4}$, and Győző Horváth² \\ ${ }^{1}$ Deutsches Meeresmuseum, Stralsund, Germany \\ ${ }^{2}$ Department of Ecology, University of Pécs, Pécs, Hungary \\ ${ }^{3}$ Department of Aquaculture, Szent István University, Gödöllö, Hungary \\ ${ }^{4}$ Friedrich-Schiller-University Jena, Jena, Germany
}

Bräger Z., Staszny Á., Mertzen M., Moritz T., Horváth G. 2017. Fish scale identification: From individual to species-specific shape variability. Acta Ichthyol. Piscat. 47 (4): 331-338.

\begin{abstract}
Background. Species identification from recovered fish scales, e.g., from the sediment or stomach contents, has proven to be problematic for clupeid species. To ensure reliable species discrimination within Clupeidae, we attempted to reveal inter- and intra-specific, as well as, the intra-individual variability of scale shape in two sympatric clupeid species the European pilchard, Sardina pilchardus (Walbaum, 1792) and the round sardinella, Sardinella aurita Valenciennes, 1847. Our aim was to test, whether the landmark-based geometric morphometric method is reliable for species identification from mixed samples.

Material and methods. The specimens of European pilchard and round sardinella were collected between May and October 2014 from the Gulf of Ambracia, Greece. The scale samples were taken from ten body areas (marked by letters A-J) of 487 specimens in total. A multiple-step analysis was conducted on randomly selected blind samples. The differences between body areas were assessed with canonical variate analysis (CVA) and discriminant function analysis (DFA) to compute generalized Mahalanobis distances $(D)$ and discriminant functions $\left(T^{2}\right)$, respectively.

Results. The CVA based on the total scale samples showed that in sardinella, all body areas differed significantly from each other $(D=2.54 \pm 0.79, P<0.001)$ except for one (area I vs. J: $D=22.36, P=0.085)$. In pilchard, two body area pairs represented non-significant group pairs (area D vs. G: $D=1.03, P=0.12$; and area F vs. G: $D=1.21, P=0.06$ ), whereas all other areas were significantly different $(D=2.43 \pm 0.88, P=0.003)$. At the last step of the blind sampling procedure, all scales were correctly classified by species with an average discrimination rate as high as $96.3 \%$.

Conclusion. In contrast to scale identification based merely on morphology, the geometric morphometric method is capable of detecting differences in scale shape from mixed samples that are unattainable with the former approach. Therefore, a more reliable and effective species identification can be accomplished from recovered scales, especially when discriminating species within the same family or genus.
\end{abstract}

Keywords: Clupeidae, fish scale identification, geometric morphometrics, pilchard, sardinella

\section{INTRODUCTION}

Scales are characteristic features for fishes and they are present in all major fish groups. Due to their morphological variability across taxa, fish scales are of high value for systematics and phylogenetic studies. Scale identification dates back over 160 years. Early research by Williamson (1851), Cockerell (1913), Chu (1935), and Lagler (1947) had demonstrated the value of scales in fish taxonomy. Later on, the development of keys and atlases based on scale characteristics allowed for more accurate identification to species level (Batts 1964, Mosher 1969, Casteel 1972, 1973, Patterson et al. 2002).
Traditionally, species identification is based on morphological characteristics. Scale characteristics such as the overall shape and structural features have proven to be useful not only for species but even for population identification, e.g., in walleye, Sander vitreus (Mitchill, 1818) (see Jarvis et al. 1978); lake whitefish, Coregonus clupeaformis (Mitchill, 1818) (see Casselman et al. 1981); Atlantic salmon, Salmo salar Linnaeus, 1758 (see de Pontual and Prouzet 1987); and striped bass, Morone saxatilis (Walbaum, 1792) (see Richards and Esteves 1997). Scale morphology allows discriminating even among fish

"Correspondence: Dr. Zsuzsanna Bräger, Deutsches Meeresmuseum, Katharinenberg 14-20, 18439 Stralsund, Germany, phone: $+49(0) 38312650370$, Fax: +49 (0) 3831 2650 209, e-mail: (ZB) suzanna.brager@gmail.com, (ÁS) staszny.adam@mkk.szie.hu, (MM) matthias_mertzen@hotmail.de, (TM) timo.moritz@meeresmuseum.de, (GYH)hgypte@gamma.ttk.pte.hu. 
populations at large spatial scales, e.g., within the great lakes system (Casselman et al. 1981) or among rivers from different drainage basins (Richards and Esteves 1997). Advances in image processing and analytical approaches nowadays allow using scale shape as a discriminator among local populations. Morphometric analysis, based on landmark data (geometric morphometric method) has been proven to be a reliable tool to differentiate congeneric species (Ibáñez et al. 2007, 2012), allowing for the identification of populations on a local and regional scale (Staszny et al. 2012, Bräger et al. 2016b) as well as among sympatric phenotypes (Garduño-Paz et al. 2010). The geometric morphometric analysis is only sensitive enough to reveal inter- and intra-specific memberships, however, when sample comparability is ensured by deriving them from the same sampling area on the fish body, usually the left flank, and consistency among samples is guaranteed (Ibáñez et al. 2007).

When fish scales are recovered from environmental or biological sources, e.g., sediment records or stomach contents, and the samples include scales of two or more species from mixed body areas ("mixed sample"), as is usually the case, the identification, until recently, was exclusively possible using the characteristic features of scale morphology. The usefulness of fish scales in the sedimentary records has been proven by several studies, e.g., in the reconstruction of paleoclimate and paleoceanographic conditions (Patterson et al. 2005); in the determination of environmental changes (Valdés et al. 2008); or in the assessment of paleoproductivity (Soutar and Isaacs 1969, Drago et al. 2009). Scales have provided similarly valuable information in studies of diet and feeding ecology by helping to identify prey items in fish (e.g., Mauchline and Gordon 1984), in birds (e.g., Ewins et al. 1994, Correia et al. 2016), and in mammals (e.g., Cottrell et al. 1996, Ford and Ellis 2006). Screening a large number of fish scales for species identification merely based on scale morphology, however, is rather time consuming. Furthermore, species determination among closely related species remains problematic (Bräger et al. 2016a).

Clupeiform species such as anchovies, herrings, shads, sardines, and their relatives possess derived cycloid scales (Bräger and Moritz 2016) that are easily shed and thus can be found in high densities in sediments or piscivorous species (Patterson et al. 2002, Correia et al. 2016, respectively). To distinguish clupeoid scales from other fish taxa is fairly easy, but the high degree of similarity in their scale morphology and the plasticity within single individuals impede species identification within families (Patterson et al. 2002, Bräger and Moritz 2016). In a previous study, Bräger et al. (2016b) showed that the scales of two sympatric clupeid species, i.e., European pilchard, Sardina pilchardus (Walbaum, 1792) and the round sardinella, Sardinella aurita Valenciennes, 1847, can be reliably discriminated using the landmark-based geometric morphometric method on scales of known origin. To ensure reliable species identification within Clupeidae, here we attempted to reveal inter- and intra- specific, as well as, the intra-individual variability of scale shape in European pilchard and round sardinella. Our aim was to test, whether the method can also be used reliably for the species identification from mixed samples using blind sampling procedure.

\section{MATERIAL AND METHODS}

Scale sampling and preparation. Scale samples from European pilchard and round sardinella were collected between May and October 2014. Specimens were purchased from commercial fishermen operating in the Gulf of Ambracia, a shallow and semi-enclosed gulf with an area of about $400 \mathrm{~km}^{2}$ in north-western Greece (Fig. 1). In total, 219 adult individuals of pilchard (mean $\mathrm{SL} \pm \mathrm{SD}: 81.7 \pm 4.68 \mathrm{~mm})$ and 268 adult individuals of sardinella (mean SL \pm SD: $155.4 \pm 8.51 \mathrm{~mm}$ ) were measured and sampled. For scale sampling, we followed the ten body areas suggested by Bräger and Moritz (2016) that cover the entire body surface.

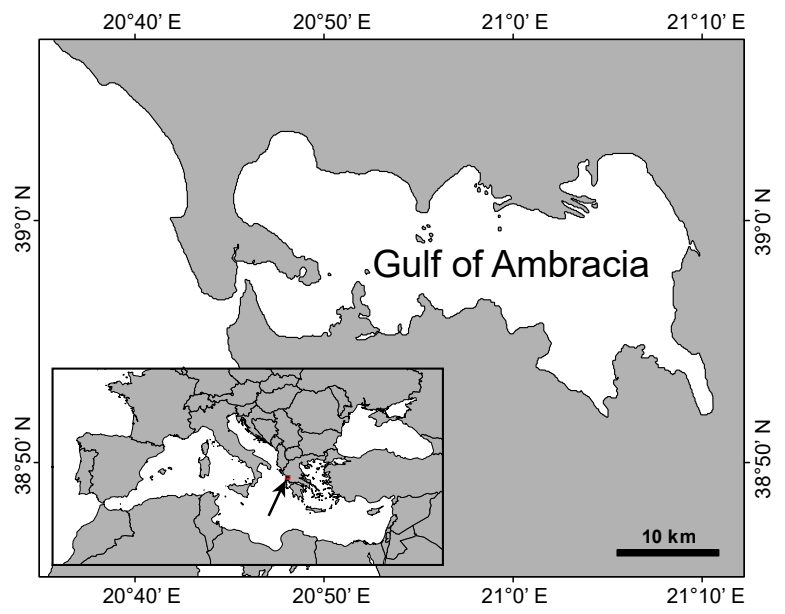

Fig. 1. The study area in north-western Greece

The exact location of these ten body areas is indicated in Fig. 2 (body areas A-J). For each specimen, only a single scale was collected from one body area on the left side of the body to avoid auto-correlation problems among scales. The number of scale samples (sampled individuals) varied for the ten sampling areas between 16 and 28 for pilchard, and from 24 to 30 for sardinella (Table 1). The scale material was stored in $70 \%$ ethanol upon collection then processed in the laboratory following the procedure described in Bräger et al. (2016b).

Data analysis. The landmark-based geometric morphometric analysis was used to determine, whether the differences in clupeid scale shape were sufficient to enable a reliable discrimination among body areas from mixed samples in pilchard and sardinella. Seven landmarks were recorded on each scale (Bräger et al. 2016b) using "tpsUtil" v. 1.60 (Rohlf 2015a) and "tpsDig2" v. 2.17 (Rohlf 2015b) utility programs to identify the key features as suggested by Staszny et al. (2012). Shape data of the scales were analysed with the software program "MorphoJ" v. 1.06d (Klingenberg 2011). Group identities (by species and by 
body areas) were assigned to raw landmark coordinates. The centroid size (CS) was used as the size metric of the scales since it constitutes the only mathematically shapefree size variable (Zelditch et al. 2004). To rotate, to scale and to align the raw coordinates into new shape variables, a Generalized Procrustes Analysis (GPA) was performed. Furthermore, a multivariate linear regression of shape (Procrustes coordinates) on size $(\log \mathrm{CS})$ was undertaken for each group to remove possible allometric effects. The significance of the relation, i.e., the presence of an allometric effect, was evaluated by using a permutation test against the null hypothesis of independence (10 000 iterations). As data were free of allometric effects associated with growth, residuals of this regression provided the basis for further analyses (Mitteroecker et al. 2013). Finally, the differences between groups were assessed with a non-parametric canonical variate analysis (CVA) and a parametric discriminant function analysis (DFA) to compute generalized Mahalanobis distances $(D)$ and discriminant functions $\left(T^{2}\right)$, respectively. The reliability of the results was examined with permutation tests with 10000 iterations.

The detailed procedure of the multi-step scale classification is as follows:
Table 1

Number of scale samples (= specimens) and body size variation between European pilchard, Sardina pilchardus and round sardinella, Sardinella aurita

\begin{tabular}{cccccc}
\hline \multirow{2}{*}{$\begin{array}{c}\text { Body } \\
\text { area }\end{array}$} & \multicolumn{2}{c}{ Pilchard } & & \multicolumn{2}{c}{ Sardinella } \\
\cline { 2 - 3 } \cline { 5 - 6 } & $N$ & SL $[\mathrm{mm}]$ & & $N$ & SL $[\mathrm{mm}]$ \\
\hline A & 21 & $82.1 \pm 5.45$ & & 30 & $153.0 \pm 5.86$ \\
B & 27 & $80.6 \pm 4.05$ & 30 & $154.0 \pm 3.99$ \\
C & 17 & $83.2 \pm 2.35$ & 30 & $156.2 \pm 5.76$ \\
D & 21 & $82.1 \pm 5.50$ & 25 & $155.2 \pm 6.70$ \\
E & 16 & $83.0 \pm 5.56$ & 24 & $151.8 \pm 4.34$ \\
F & 20 & $81.7 \pm 5.18$ & 26 & $156.9 \pm 4.15$ \\
G & 27 & $80.7 \pm 4.34$ & 26 & $155.2 \pm 5.34$ \\
H & 28 & $81.1 \pm 4.68$ & 25 & $156.1 \pm 5.69$ \\
I & 16 & $82.9 \pm 5.51$ & 26 & $154.0 \pm 2.87$ \\
J & 26 & $80.9 \pm 3.83$ & 26 & $156.9 \pm 4.03$ \\
\hline Total & 219 & $81.7 \pm 4.68$ & 268 & $155.4 \pm 8.51$ \\
\hline
\end{tabular}

Body areas (A-J) are visualised in Fig. 2 (after Bräger and Moritz 2016); $N=$ number of scales, $\mathrm{SL}=$ standard length (mean \pm standard deviation).

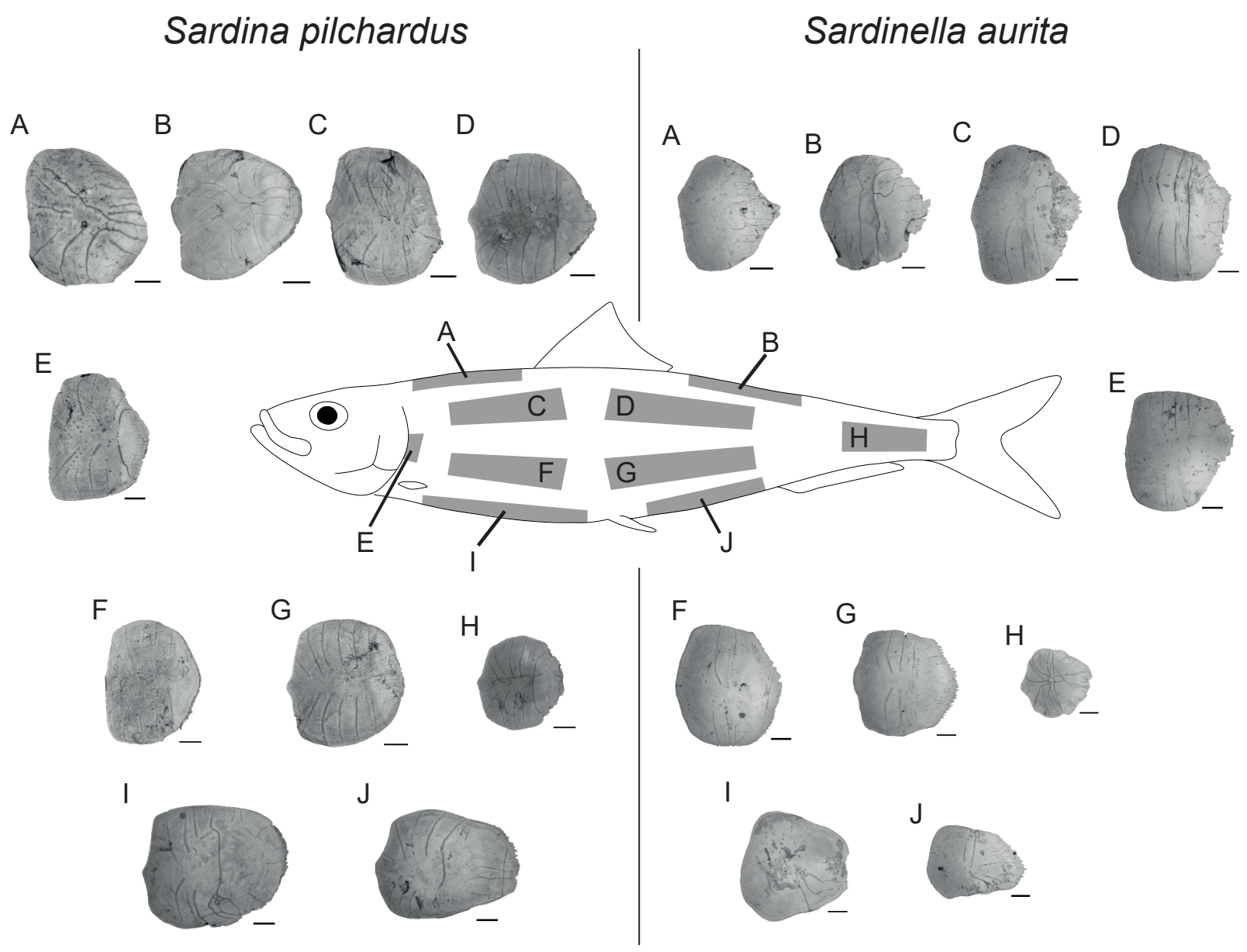

Fig. 2. Scale shape variation among body areas in European pilchard, Sardina pilchardus, and round sardinella, Sardinella aurita; scales are oriented with the anterior (rostral) part to the left of the image; scale bar = $1 \mathrm{~mm}$; the schematic drawing of a clupeid fish with the sampling areas is adopted from Bräger and Moritz (2016) 
- Examining the discrimination of scale shapes among body areas within species.

- Randomly selecting 5 scales within each body area in both species and using them as blind samples.

- Testing whether each blind sample can be identified on species level:

- Blind sample compared to the scale shapes of the full reference database (i.e., all body areas) of the two species (classification Type I).

- Blind sample compared to the scale shapes of the body areas (independently of the species).

- Comparison of scale shapes from body areas that showed non-significant differences at the species level (classification Type II).

Although the Type II classification was not necessary to be run in every case, for testing purposes it was performed for the entire dataset. With this iterative, "stepby-step" comparison, the species-level identification was also possible in those cases, when Type I classification failed (e.g., if significant differences between the blind samples and their original species were present).

\section{RESULTS}

In both clupeid species, the general pattern of scale shape changed according to the area of origin on the fish body. The most typical shapes among body areas varied from circular, cordate, to oval, even to slightly quadrilateral. Scales derived from the mid-lateral region of the fish body (areas C, D, E, F, and G) were extended in the dorsoventral axis, whereas scales from the dorsal or ventral edges of the body (areas A, B or I, J, respectively) were rather compressed or elongated in the anteroposterior axis. This elongation was found to be the most prominent in the ventral areas (I and J). Caudal peduncle scales (area $\mathrm{H}$ ) were characterized by being relatively shorter in the anteroposterior axis resulting in a circular appearance of the scales (Fig. 2).

The regression of scale shape (using Procrustes coordinates) on scale centroid size indicated notable allometry (dependence of shape on size) among body areas in both species (in pilchard: $2.54 \%, P<0.001$; in sardinella: $1.01 \%, P=0.016)$. The mean scale shape among body areas of the two species showed different levels of overlap in the CVA with definite separation of the two species (Fig. 3). The areas of the mid-lateral region, i.e., $\mathrm{C}-\mathrm{B}, \mathrm{D}-\mathrm{B}, \mathrm{G}-\mathrm{B}, \mathrm{D}-\mathrm{G}$, and $\mathrm{F}-\mathrm{G}$ in case of pilchard, as well as areas $F$ and $G$ in case of sardinella proved to be the most similar in their average scale shape (e.g., lowest Mahalanobis distances), whereas certain pairs of areas $\mathrm{B}-\mathrm{I}, \mathrm{C}-\mathrm{I}$, and $\mathrm{H}-\mathrm{I}$ in pilchard and $\mathrm{E}-\mathrm{I}$ and $\mathrm{D}-\mathrm{I}$ in sardinella differed most from each other. The CVA based on total scale samples (see Table 2) showed that in pilchard two body area-pairs represented a non-significant group pairs (area D vs. area G: $D=1.03, P=0.12$; and area $\mathrm{G}$ vs. area $\mathrm{F}: D=1.21, P=0.06$ ), whereas all other areas were significantly different from each other $(D=2.43 \pm$ $0.88, P<0.001)$. In sardinella, two body areas represented a non-significant pair (area I vs. J: $D=22.36, P=0.085$ ), whereas all other areas were significantly different from each other $(D=2.54 \pm 0.79, P<0.001)$. Between the two

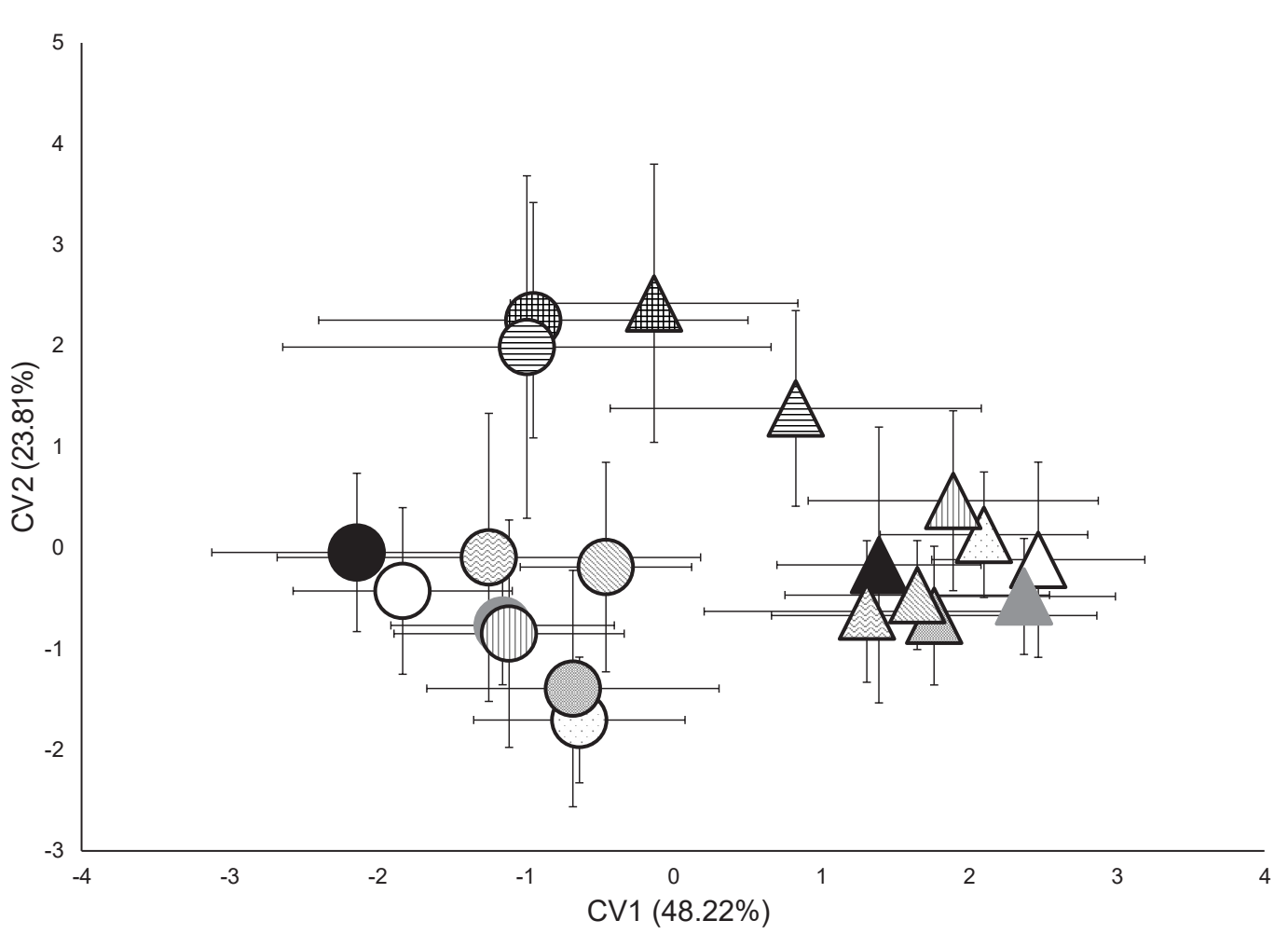

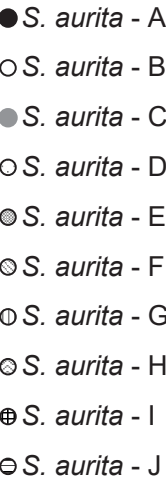

$\Delta$ S. pilchardus - A

$\triangle S$. pilchardus - B

$\triangle S$. pilchardus - C

$\triangle S$. pilchardus - D

$\Delta S$. pilchardus - E

$\Delta S$. pilchardus - $\mathrm{F}$

$\Delta S$. pilchardus - G

$\Delta S$. pilchardus - $\mathrm{H}$

$\Delta S$. pilchardus - I

$\Delta S$. pilchardus - J

Fig. 3. Canonical variate analysis results comparing scale shapes among body areas in European pilchard, Sardina pilchardus, and round sardinella, Sardinella aurita; symbols show the group means of body areas (see Fig. 2); crosshairs show standard deviations 


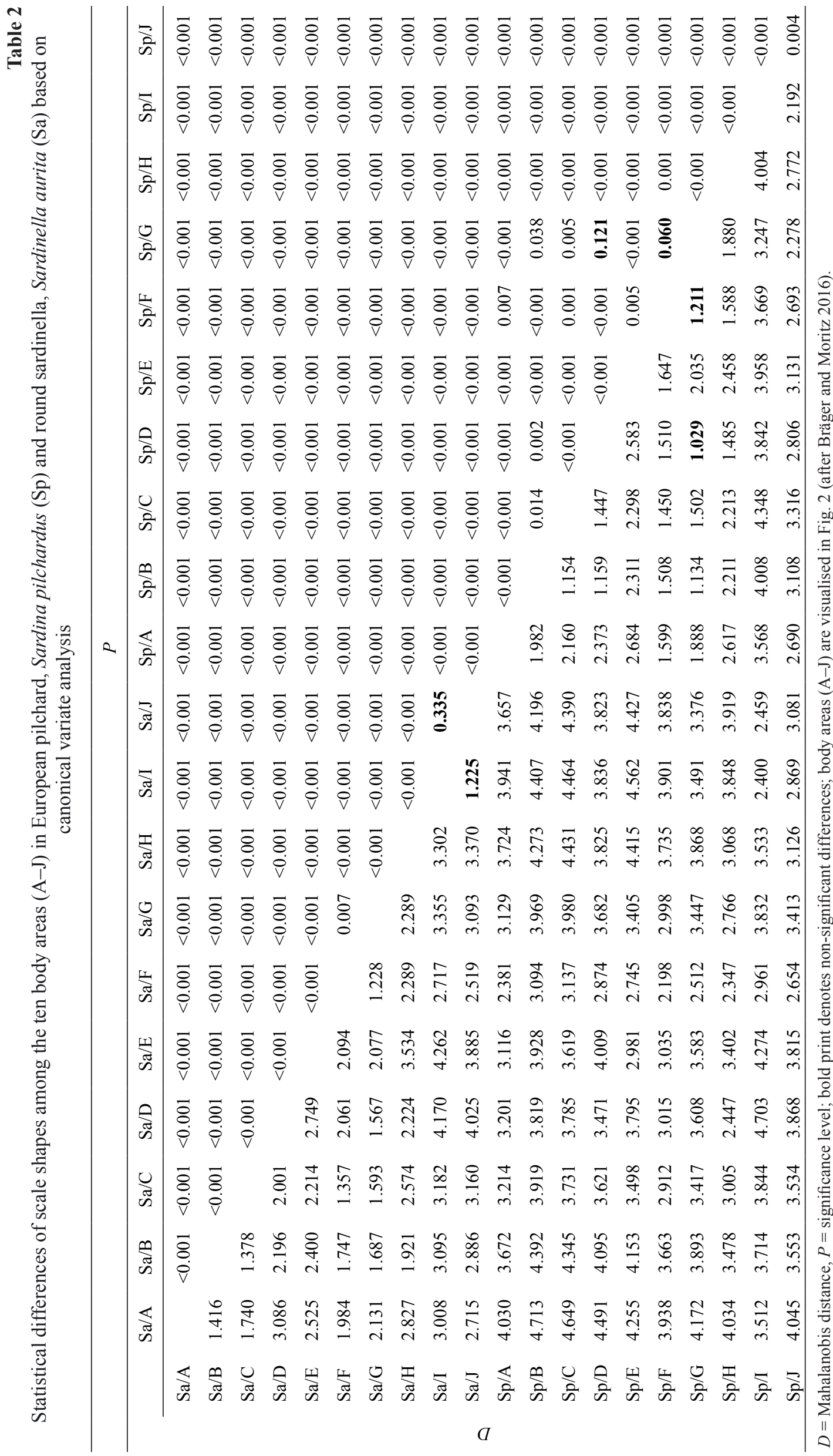


species, scales of all body areas differed significantly and at much higher statistical distances $(D=3.61 \pm 0.59, P<$ $0.001)$. The validity of the results was confirmed by the large proportion of correct classifications with an average discrimination rate of $96.3 \%$ based on cross-validation. The detailed results of the blind sample classification based on randomly selected scales within each of the body areas are summarized in Tables 3 and 4 . In most cases (in pilchard: body area B, C, D, E, F, G, H, J; in sardinella: body area A, B, C, D, E, F, I, J), the Type I classification was sufficient to classify a blind sample correctly at specieslevel (e.g., with a non-significant difference from own species). In those cases, when the blind sample differed significantly from the entire sample of the species (i.e., in pilchard: area A and area I; in sardinella: area $G$ and area $\mathrm{H}$ ), the Type II classification could classify the blind sample well to the species (i.e., non-significant differences from the species).

\section{DISCUSSION}

Scales of many fish taxa show variable shapes and possess a high degree of morphological plasticity within species and specimens, often making clear identification at species level difficult from recovered scale samples. This applies, particularly to clupeiform fishes. Several small pelagic fish species belonging to this order support some of the largest fisheries on Earth (Anonymous 2016) and play a crucial role in marine ecosystems, because their large biomass poses a critical link in marine food webs
(Ganias 2014). Reliable and rapid species identification of this group from environmental samples would provide valuable information, for example, for fisheries (e.g., by discriminating species and stocks), foraging ecology (e.g., by identifying them as prey items) and paleoclimatic and paleoceanographic investigations (e.g., by determining species composition in sediment samples).

In the presently reported study, scales from different body areas of the European pilchard and the round sardinella were successfully classified and discriminated in mixed samples. Although there are a few body areas that show similarities in scale shape within the same species, the last step of our multi-step analysis correctly classified among the body areas of each of the two species. Only scales from body area $\mathrm{J}$ (posterior ventral area) in pilchard could not be discriminated reliably from sardinella in the final step (Type II) but were already classified correctly in an earlier step (Type I). The DFA showed a significant difference between the two species for area $J$ when the analysis was run again for sardinella. To increase the reliability of the analysis, elongated scales derived from either the dorsal or ventral edges of the fish body (areas A, B and I, J, respectively) might be disregarded for identification purposes. Our findings agree with those of Ibáñez and O'Higgins (2011) who also found scales of the mid-section of fish to be most useful for this identification method.

Scales that represent the typical round shape properties for a clupeid species are generally located on the flanks

Results of the blind sample classification in European pilchard, Sardina pilchardus

Table 3

\begin{tabular}{|c|c|c|c|c|c|c|c|c|c|c|}
\hline \multirow{2}{*}{ Classification } & \multicolumn{10}{|c|}{ Body area } \\
\hline & A & B & $\mathrm{C}$ & D & E & $\mathrm{F}$ & G & $\mathrm{H}$ & I & $\mathrm{J}$ \\
\hline Type I $(D / P)$ & $2.04 / 0.041$ & $1.33 / 0.48$ & $3.43 / 0.37$ & $1.39 / 0.42$ & $0.99 / 0.85$ & $0.76 / 0.97$ & $1.12 / 0.74$ & $1.81 / 0.11$ & $2.94 /<0.001$ & $1.78 / 0.13$ \\
\hline $\begin{array}{l}\text { Non-significant } \\
\text { differences }\end{array}$ & $\mathrm{A}, \mathrm{G}$ & $\mathrm{B}, \mathrm{G}, \mathrm{H}$ & $\mathrm{B}, \mathrm{C}, \mathrm{E}, \mathrm{G}$ & $\mathrm{D}, \mathrm{E}, \mathrm{G}$ & $\mathrm{E}, \mathrm{G}$ & $\begin{array}{c}\text { A, B, C, E, } \\
F, G, H, J\end{array}$ & A, B, E, G & $\mathrm{G}, \mathrm{H}$ & I & $\mathrm{H}, \mathrm{J}$ \\
\hline Type II $(D / P)$ & $1.93 / 0.15$ & $1.06 / 0.77$ & $1.41 / 0.5$ & $1.08 / 0.83$ & $1.14 / 0.82$ & $0.81 / 0.96$ & $0.94 / 0.95$ & $1.44 / \mathbf{0 . 2 9}$ & $1.08 / 0.91$ & $1.56 / \mathbf{0 . 2 1}$ \\
\hline Type II $\left(T^{2} / P\right)$ & $15.14 / 0.29$ & $9.54 / 0.58$ & $7.54 / 0.74$ & $7.12 / 0.79$ & $4.55 / 0.95$ & $3.08 / 0.98$ & $3.44 / 0.98$ & $10.84 / 0.53$ & $6.25 / 0.95$ & $12.24 / \mathbf{0 . 4 3}$ \\
\hline
\end{tabular}

Body areas (A-J) are visualised in Fig. 2 (after Bräger and Moritz 2016); classification of groups: Type I = CVA-based on the total scale samples, Type II = CVA- and DFA-based on the non-significant sampling areas, CVA = canonical variate analysis, DFA = discriminant function analysis; $D=$ Mahalanobis distance, $T^{2}=$ discriminant functions, $P=$ significance level; bold print denotes non-significant differences in body areas between pilchard and sardinella.

Table 4

Results of the blind sample classification in round sardinella, Sardinella aurita;

\begin{tabular}{|c|c|c|c|c|c|c|c|c|c|c|}
\hline \multirow{2}{*}{ Classification } & \multicolumn{10}{|c|}{ Body area } \\
\hline & A & B & $\mathrm{C}$ & $\mathrm{D}$ & $\mathrm{E}$ & $\mathrm{F}$ & G & $\mathrm{H}$ & I & $\mathrm{J}$ \\
\hline Type I $(D / P)$ & $1.86 / 0.12$ & $1.5 / 0.35$ & $1.21 / 0.63$ & $2.03 / 0.07$ & $1.76 / 0.17$ & $0.62 / 0.99$ & $2.48 / 0.01$ & $2.48 / 0.01$ & $2.08 / 0.06$ & $1.96 / 0.1$ \\
\hline $\begin{array}{l}\text { Non-significant } \\
\text { differences }\end{array}$ & $\mathrm{A}, \mathrm{J}$ & $\begin{array}{l}\text { A, B, } \\
\mathrm{H}, \mathrm{J}\end{array}$ & $\begin{array}{c}\mathrm{A}, \mathrm{B}, \mathrm{C}, \mathrm{E}, \\
\text { G, H }\end{array}$ & $\mathrm{D}, \mathrm{H}$ & $\mathrm{E}$ & $\begin{array}{l}\text { A, B, C, E, } \\
\text { F, G, H, J }\end{array}$ & $\mathrm{H}$ & $\mathrm{H}$ & $\mathrm{I}, \mathrm{J}$ & $\mathrm{H}, \mathrm{I}, \mathrm{J}$ \\
\hline Type II $(D / P)$ & $1.4 / 0.41$ & $1.26 / 0.6$ & $1.12 / 0.74$ & $1.17 / 0.83$ & $1.00 / 0.94$ & $0.53 / 0.99$ & $1.52 / 0.71$ & $1.52 / 0.71$ & $1.28 / 0.64$ & $1.27 / 0.69$ \\
\hline Type II $\left(T^{2} / P\right)$ & $9.65 / 0.59$ & $9.07 / 0.59$ & $5.83 / 0.85$ & $5.37 / 0.92$ & $6.6 / 0.91$ & $1.34 / 0.99$ & $7.26 / 0.87$ & $7.26 / 0.87$ & $6.99 / 0.82$ & $7.35 / 0.76$ \\
\hline
\end{tabular}

Body areas (A-J) are visualised in Fig. 2 (after Bräger and Moritz 2016); classification of groups: Type I = CVA-based on the total scale samples, Type II = CVA- and DFA-based on the non-significant sampling areas, CVA = canonical variate analysis, DFA = discriminant function analysis; $D=$ Mahalanobis distance, $T^{2}=$ discriminant functions, $P=$ significance level; bold print denotes non-significant differences in body areas between pilchard and sardinella. 
and the lateral mid-section of the fish body (i.e., areas C, D, F, and G). According to the study of Shackleton (1988), scales from these body areas (i.e., "typical scales") were observed in high numbers in the sediments, as well as in samples collected during predatory behaviour of bottlenose dolphins (Bräger et al. 2016a). Clupeiformes tend to lose their scales easily (Patterson et al. 2002), thus the occurrence of typical clupeiform scales in sediments or biological samples is high (Drago et al. 2009, Bräger et al. 2016a). Our investigation showed that the rate of correct classification of scales from the above-mentioned body areas (i.e., lateral mid-section of the fish body) was the highest; therefore the reliability of identifying them among recovered scales has a high likelihood. The large proportion of correct classifications, as well as the high number of examined scale samples, further increase the efficiency of species identification from mixed samples in environmental or biological sources. The geometric morphometric method eliminates any effect of allometric growth when using the centroid size of the scales as the size metric, followed by a linear regression and permutation tests. Therefore, knowing the exact length of the specimen that the scales originate from, which is an essential component of the standardizing process in the traditional morphometrics, is no longer needed for the analysis. Our results provide a reliable and efficient way for scale identification in paleontological and dietary studies that can help to overcome the limitations of morphological analyses used in former studies (e.g., Drago et al. 2009, Bräger et al. 2016a).

\section{ACKNOWLEDGEMENT}

We are grateful to Harald Benke and Stefan Bräger for logistical support, as well as to Ioannis Avlonitis, Julianna Pereszlényi, Joan Gonzalvo, and Viktoria Kretz for their help in the collection of fish scales from the Gulf of Ambracia. Furthermore, we thank to Kioshi Mishiro for creating the map of the Gulf of Ambracia.

\section{REFERENCES}

Anonymous 2016. The state of world fisheries and aquaculture 2016. Contributing to food security and nutrition for all. FAO, Rome.

Batts B.S. 1964. Lepidology of the adult pleuronectiform fishes of Puget Sound, Washington. Copeia 1964 (4): 666-672.

DOI: $10.2307 / 1441441$

Bräger Z., Gonzalvo J., Agazzi S., Bearzi G. 2016a. Identification of bottlenose dolphin(Tursiops truncatus) prey using fish scale analysis. Aquatic Mammals 42 (1): 63-73.

DOI: $10.1578 /$ AM.42.1.2016.63

Bräger Z., Moritz T. 2016. A scale atlas for common Mediterranean teleost fishes. Vertebrate Zoology 66 (3): 275-388.

Bräger Z., Moritz T., Tsikliras A.C., Gonzalvo J., Radulović M., Staszny Á. 2016b. Scale morphometry allows discrimination of European sardine Sardina pilchardus and round sardinella Sardinella aurita and among their local populations. Journal of Fish Biology 88 (3): 1273-1281.

DOI: $10.1111 / \mathrm{jfb} .12907$

Casselman J.M., Collins J.J., Grossman E.J., Ihssen P.E., Spanger G.R. 1981. Lake whitefish (Coregonus clupeaformis) stocks of the Ontario waters of Lake Huron. Canadian Journal of Fisheries and Aquatic Sciences 38 (12): 1772-1789.

DOI: $10.1139 / \mathrm{f} 81-225$

Casteel R.W. 1972. A key, based on scales, to the families of native California freshwater fishes. Proceedings of the California Academy of Sciences 39 (4): 75-86.

Casteel R.W. 1973. The scales of the native freshwater fish families of Washington. Northwest Science 47 (4): 230-238.

Chu Y.T. 1935. Comparative studies on the scales and on the pharyngeals and their teeth in Chinese cyprinids, with particular reference to taxonomy and evolution. Biological Bulletin of St. John's University 2: 1-225.

Cockerell T.D.A. 1913. Observations on fish scales. Bulletin of the United States Bureau of Fisheries 32: 119-174.

Correia A., Ramos J.A., Paiva V.H. 2016. Identifying the diet of the little tern (Sternula albifrons). Waterbirds 39 (3): 318-322.

DOI: $10.1675 / 063.039 .0313$

Cottrell P.E., Miller E.H., Trites A.W. 1996. Assessing the use of hard parts in faeces to identify harbour seal prey: Results of captive-feeding trials. Canadian Journal of Zoology 74 (5): 875-880.

DOI: $10.1139 / \mathrm{z} 96-101$

de Pontual H., Prouzet P. 1987. Atlantic salmon, Salmo salar L., stock discrimination by scale shape analysis. Aquaculture Research 18 (3): 277-289.

DOI: $10.1111 / \mathrm{j} .1365-2109.1987 . t b 00147 . x$

Drago T., Ferreira-Bartrina V., Santos A.M.P., Pinheiro J. 2009. The use of fish remains in sediments for the reconstruction of paleoproductivity. IOP Conference Series: Earth and Environmental Science 5: 012012. DOI: $10.1088 / 1755-1307 / 5 / 1 / 012012$

Ewins P.J., Weseloh D.V., Groom J.H., Dobos R.Z., Mineau P. 1994. The diet of herring gulls (Larus argentatus) during winter and early spring on the lower Great Lakes. Hydrobiologia 279 (1): 39-55. DOI: $10.1007 / \mathrm{BF} 00027839$

Ford J.K.B., Ellis G.M. 2006. Selective foraging by fisheating killer whales Orcinus orca in British Columbia. Marine Ecology Progress Series 316: 185-199. DOI: $10.3354 / \operatorname{meps} 316185$

Ganias K. 2014. Biology and ecology of sardines and anchovies. CRC Press: Taylor and Francis Group, Boca Raton, FL, USA. DOI: $10.1201 / \mathrm{b} 16682$

Garduño-Paz M.V., Demetriou M., Adams C.E. 2010. Variation in scale shape among alternative sympatric phenotypes of Arctic charr Salvelinus alpinus from two lakes in Scotland. Journal of Fish Biology 76 (6): 1491-1497.

DOI: $10.1111 /$ j.1095-8649.2010.02584.x 
Ibáñez A.L., Cowx I.G., O’Higgins P. 2007. Geometric morphometric analysis of fish scales for identifying genera, species, and local populations within the Mugilidae. Canadian Journal of Fisheries and Aquatic Sciences 64 (8) 1091-1100.

DOI: $10.1139 /$ f07-075

Ibáñez A.L., Espino-Barr E., Gallardo-Cabello M. 2012. Population connectivity among geographic variants within the Lutjanidae (Pisces) of the Mexican Pacific coast through fish scale shape recognition. Scientia Marina 76 (4): 667-675.

DOI: $10.3989 /$ scimar.03675.09C

Ibáñez A.L., O’Higgins P. 2011. Identifying fish scales: The influence of allometry on scale shape and classification. Fisheries Research 109 (1): 54-60.

DOI: 10.1016/j.fishres.2011.01.016

Jarvis R.S., Klodowski H.F., Sheldon S.P. 1978. New method of quantifying scale shape and an application to stock identification in walleye (Stizostedion vitreum vitreum). Transactions of the American Fisheries Society 107 (4): 528-534.

DOI:10.1577/1548-8659(1978)107<528:NMOQSS>2.0.CO;2

Klingenberg C.P. 2011. MorphoJ: an integrated software package for geometric morphometrics. Molecular Ecology Resources 11 (2): 353-357.

DOI: $10.1111 / \mathrm{j} .1755-0998.2010 .02924 . x$

Lagler K.F. 1947. Lepidological studies 1. Scale characters of the families of Great Lake fishes. Transactions of the American Microscopical Society 66 (2): 149-171. DOI: $10.2307 / 3223246$

Mauchline J., Gordon J.D.M. 1984. Occurrence of stones, sediment and fish scales in stomach contents of demersal fish of the Rockall Trough. Journal of Fish Biology 24 (4): 357-362.

DOI: $10.1111 /$ j.1095-8649.1984.tb04808.x

Mitteroecker P., Gunz P., Windhager S., Schaefer K. 2013. A brief review of shape, form, and allometry in geometric morphometrics, with applications to human facial morphology. Hystrix, the Italian Journal of Mammalogy 24 (1): 59-66.

DOI: $10.4404 /$ hystrix-24.1-6369

Mosher K.H. 1969. Identification of Pacific salmon and steelhead trout by scale characteristics. United States Department of the Interior, Fish and Wildlife Service, Bureau of Commercial Fishes; Circular 317.

Patterson R.T., Prokoph A., Kumar A., Chang A.S., Roe H.M. 2005. Late Holocene variability in pelagic fish scales and dinoflagellate cysts along the west coast of Vancouver Island, NE Pacific Ocean. Marine Micropaleontology 55 (3-4): 183-204.

DOI: 10.1016/j.marmicro.2005.02.006

Patterson R.T., Wright C., Chang A.S., Taylor L.A., Lyons P.D., Dallimore A., Kumar A. 2002. Atlas of common squamatological (fish scale) material in coastal British Columbia and an assessment of the utility of various scale types in paleofisheries reconstruction. Palaeontologia Electronica 4 (1): 1-88.

Richards R.A., Esteves C. 1997. Use of scale morphology for discriminating wild stocks of Atlantic striped bass. Transactions of the American Fisheries Society 126 (6): 919925.

DOI: 10.1577/1548-8659(1997)126<0919:UOSMFD>2.3.CO;2

Rohlf F.J. 2015a. TpsUtil, file utility program, version 1.60. Department of Ecology and Evolution, State University of New York at Stony Brook. http://life.bio.sunysb.edu/morph

Rohlf F.J. 2015b. TpsDig, digitize landmarks and outlines, version 2.17. Department of Ecology and Evolution, State University of New York at Stony Brook. http://life.bio.sunysb. edu/morph/soft-dataacq.html

Shackleton L.Y. 1988. Scale shedding: An important factor in fossil fish studies. Journal du Conseil international pour l'Exploration de la Mer 44 (33): 259-263.

DOI: $10.1093 /$ icesjms/44.3.259

Soutar A., Isaacs J.D. 1969. History of fish populations inferred from fish scales in anaerobic sediments off California. California Cooperative Oceanic Fisheries Investigations 13: 63-70.

Staszny Á., Ferincz Á., Weiperth A., Havas E., Urbányi B., Paulovits G. 2012. Scale-morphometry study to discriminate Gibel carp (Carassius gibelio) populations in the Balatoncatchment (Hungary). Acta Zoologica Academiae Scientiarum Hungaricae 58 (1): 19-27.

Valdés J., Ortlieb L., Gutierrez D., Marinovic L., Vargas G., Sifeddine A. 2008. 250 years of sardine and anchovy scale deposition record in Mejillones Bay, northern Chile. Progress in Oceanography 79 (2-4): 198-207.

DOI: $10.1016 /$ j.pocean.2008.10.002

Williamson W.C. 1851. [XXIX.] Investigations into the structure and development of the scales and bones of fishes. Philosophical Transactions of the Royal Society of London 141: 643-702.

DOI: $10.1098 /$ rstl.1851.0033

Zelditch M.L., Swiderski D.L., Sheets H.D., Fink W.L. 2004. Geometric morphometrics for biologists: A primer. Elsevier Academic Press, Amsterdam. 